\title{
Isochronal Map of Fresh Fruits and Vegetable Transporta- tion from the Mt. Kenya Region to Nairobi
}

\author{
PETER DANNENBERG ${ }^{1}$, MANUELA KUNZE ${ }^{2}$ and GILBERT M. NDURU ${ }^{3}$ \\ ${ }^{1}$ Department of Geography, Humboldt-University at Berlin, Unter den Linden 6, 10099 Berlin, Germany; peter.dannenberg@geo.hu- \\ berlin.de. \\ ${ }^{2}$ FB III Labor Geodatenanalyse und Visualisierung, Beuth University of Applied Science, Luxemburger Straße 10, 13353 Berlin, \\ Germany. \\ ${ }^{3}$ Department of Geography, Moi University, P.O. Box 3900, Eldoret 30100, Kenya.
}

\begin{abstract}
Developing countries like Kenya face problems of poor transportation networks, which make the timedistance relationship in the transportation of fresh fruit and vegetables (FFV) products to be of great importance in determining whether the products reach the market fresh and in marketable quality. This map demonstrates that relationship using the case of the Mt. Kenya region. It highlights the quality and extent of the road infrastructure in the region and the relative time and distance that FFV producers and transporters take to transport their products to the main export point at the Jomo Kenyatta International Airport (JKIA) in Nairobi.
\end{abstract}

(Received $8^{\text {th }}$ December 2010; Revised $25^{\text {th }}$ June 2011; Accepted 19th July 2011) 


\section{Introduction}

The Mt. Kenya region is a typical export-based fresh fruit and vegetables (FFV) production area in Kenya. Today FFV production has become the most important form of livelihood in the region. Export products are commonly french beans, snow peas, avocados and mangos. In 2005 about 4,000 mostly small scale ( $<10$ ha) horticultural farmers were producing FFV for export in the area (Mithofer et al., 2008). Almost all products sold for export are transported to Nairobi by road first where they are airlifted to their foreign destinations (mainly the European Union) via the Jomo Kenyatta International Airport (JKIA). Road transport is the only mode of transportation for FFV products from the region to Nairobi. The region is served by an all weather ring-road that runs around Mt. Kenya and which is fed by numerous secondary and tertiary link roads that serve the farming areas. Transportation on the main road is smooth, but the secondary and tertiary link roads are generally rough and often impassable, especially during the wet season. This often results to unnecessary delays and the destruction of products in transit to Nairobi.

To get their products to Nairobi, most producers in Mt. Kenya are dependent on transporters and/or exporters. There are a number of variables that these traders use to determine the prices paid to farmers, one of the most crucial is the quality in which the product arrives at the consumer and this is highly related to the travel time to the export hub. Previous studies on Kenyan FFV production show that the time taken in transit to the Nairobi drop-in centre, has direct and indirect effects on the economic performance of the farmers (McCulloch and Ota, 2002; Dannenberg, 2008).

Regarding the direct effects, first, a longer transport time increases the costs. This is mainly due to costs deducted from their earnings to pay for tr and other related costs including vehicular breakages and insurance against possible losses. Second, a longer transport time negatively effects the quality of the highly perishable goods and increases the rate of wastage (McCulloch and Ota, 2002). Third, farmers facing a lengthy travel time to Nairobi have less opportunities to sell directly to the export companies or to get contracted in out-grower schemes (Dannenberg, 2008; Mithofer et al., 2008). Because of the lengthy time lapse, the farmers increasingly sell their produce not directly to an exporter but to middlemen who transport the products to an exporter in Nairobi. These middlemen usually pay lower prices than the exporters. In addition, the involvement of middlemen reduces farmer access to business-relevant information (e.g. on pricing and other market developments). An increase in travel time has a negative effect on the information flow between the farmer and the market region (Dannenberg, 2008).

As a result of the challenges associated with transportation distances and time taken to JKIA, experts see an urgent need for considerable investment into transport and other related infrastructure (McCulloch and Ota, 2002). However, data on how distance is 
linked to a bad road network, and not only to spatial distances, are rare. Our article and map provides useful information, which can be used in combination with other data, to develop policy recommendations for road network and land use planning. Based on the given background this paper analyses and maps how far the time distance from the producer to Nairobi is influenced by the actual transport infrastructure.

\section{Data Analysis}

Data on the road network in the Mt. Kenya region was acquired from several different sources including the Kenyan Roads Board, the Kenyan National Highway Authority and the United Nations Joint Logistics Center. Data on road types and possible speeds on different types or sections of roads in Kenya was acquired from the International Livestock Research Institute (ILRI, 2007). According to ILRI, official Kenyan roads can be categorized in three classes based on maximum possible speed, road width, surface condition and obstacles (Figure 1):
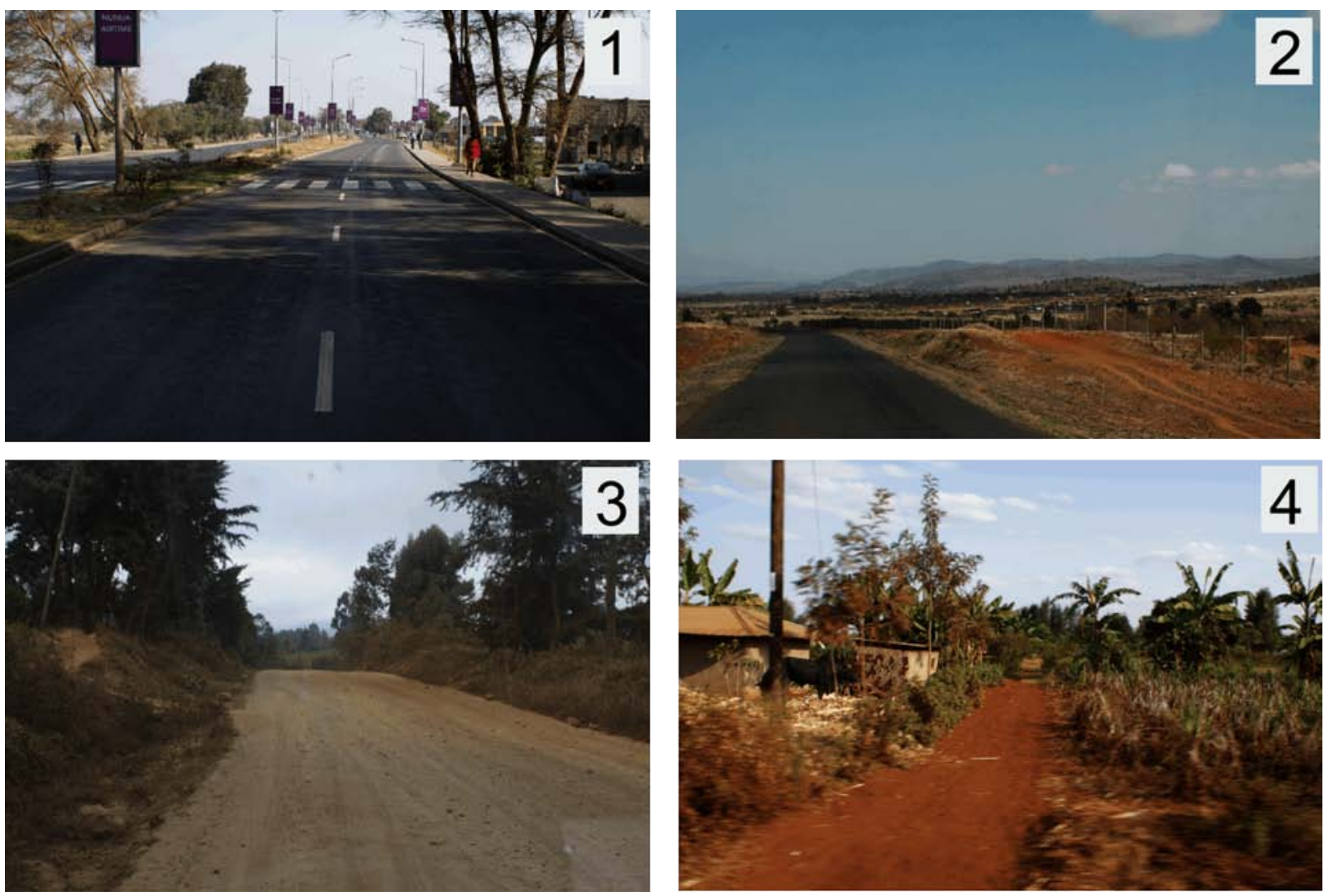

Figure 1. Plates : 1, 2, 3 and 4 showing different road classes (class 1, 2, 3 and 4, respectively). Photos: S. Huber and M. Kunze. 
Class 1: These are roads on which a maximum speed of $80 \mathrm{~km} / \mathrm{h}$ is permitted in Kenya. They have two or more lanes for each direction and are characterized by a closed paved surface. Their condition is generally good. Besides a few speed ramps close to villages or dangerous road sections, other obstacles are unlikely to be found.

Class 2: These roads notably reduce the maximum possible speed to $55 \mathrm{~km} / \mathrm{h}$. They show one lane in each direction, hence the road allows for two vehicles side by side. Lane markings are often absent. The asphalt cover is not complete in many instances due to damage in the form of pot holes, cracks, and breaking edges. Crossing cattle can slow down the travel speed of vehicles considerably.

Class 3: These are all 'seasons' roads whose surface is made of gravel, sand, murran and/or ballast, which makes them generally rough. They can allow speeds of up to 30 $\mathrm{km} / \mathrm{h}$ since beyond that limit vehicles and products may be damaged.

Class 4: In addition further paths and roads exists which are not included in the classification but are heavily used in rural areas (for other African examples on such roads see e.g. Bryceson et al., 2003). These roads are usually passable only during the dry season. They are generally rough and the maximum possible speeds are significantly lower than $30 \mathrm{~km} / \mathrm{h}$. However, the lack of data and the scale of the map inhibit the inclusion of these roads in the map analysis. Nevertheless, they result in high transportation costs, which as noted from our study, have caused many small scale farmers to drop out of the FFV export business.

Apart from not including class 4 roads, the ILRI data has further weaknesses. Interviews with local experts and our own investigations in the region showed that some roads in the Mt. Kenya region, which fulfil the attributes for a classification 1-3 were not included in the ILRI data set. Also several roads were erroneously categorized. Reasons for these inconsistencies can be seen in infrastructure projects and road degradation (e.g. due to erosion) since the collection of the ILRI data.

To reduce these weaknesses we adjusted the ILRI data with our own data collected during fieldwork in the Mount Kenya Region in 2009. These data revealed several new roads that had not been identified and classified by ILRI, while some other formerly good roads had deteriorated. The road outline data was obtained using a handheld-GPS in a geographic coordinate system (Datum/Ellipsoid: WGS84). In total, five new roads were added and classified and five roads were reclassified in comparison to the ILRI classification with regard to possible speeds (as measured via GPS), road width, surface condition, and road obstacles. The background of map 1, was made using the digital elevation model GDEM (Global Digital Elevation Model) based on ASTER (Advanced Spaceborn Thermal Emission and Reflection Radiometer; ASTER, 2009) satellite images. 


\section{Methods}

The dataset outlined in the previous section was entered in an ArcGIS Model via ArcGIS Model Builder. Spatial Analyst was used for working with raster datasets in process chain. Based on a focal-cell at Nairobi Airport the costs of travelling to every cell in the raster were accumulated by the ArcGIS "Cost-Distance" function. In this case the term 'cost' has a more general meaning than financial costs. It represents the effort of travelling across one cell in the raster dataset. The analysis was based on the different velocities of the three kinds of roads in the Mount Kenya Region $(80 \mathrm{~km} / \mathrm{h}, 55 \mathrm{~km} / \mathrm{h}$ and $30 \mathrm{~km} / \mathrm{h}$ ). The transportation time of FFV from the farms to Nairobi was estimated by this model. Finally we used interviews with farmers and five local stakeholders for the interpretation of the data.

\section{Results}

Map 1 gives an overview of the structure of the road system in the Mt. Kenya region. Black heavy-weight lines show Class 1 roads $(80 \mathrm{~km} / \mathrm{h})$, while medium-weight lines represent second class roads with a loose surface and a maximum speed of nearly 55 $\mathrm{km} / \mathrm{h}$. All light-weight lines mark Class 3 roads.

The colour gradient in map 2 from green to red illustrates the different durations taken in transit to Nairobi. This demonstrates that farmers served with class 1 roads are able to get their produce to Nairobi in the shortest time possible from their relative locations as compared to others, who have to use other classes of roads before linking up with a Class 1 road. Moreover, the FFV farmers in the west, east and south of Mount Kenya are relatively closer to Nairobi that others. For example, FFV farmers around Embu, are able to take their produce to Nairobi within an average time of 90 minutes. However, FFV farmers in the northern parts of the region travel longer distances and hence spend more time due to the absence of a direct connection to bypass the mountain. In addition to distance, one also has to keep in mind several other factors which influence travel time. The map shows that the time-distance to Nairobi is only partly related to the spatial distance of the location to Nairobi. Access to good road networks is of fundamental importance as well. This can be verified by comparing two different locations. Rugirando village is $219 \mathrm{~km}$ away from Nairobi and the nearest classified road is Class 3. Mitunguu village in turn is $221 \mathrm{~km}$ away but is closely connected to a Class 1 road. While both villages have more or less the same spatial distance to Nairobi, the time-distance from Rugirando to Nairobi is 284 minutes, $102 \mathrm{~min}(56 \%)$ slower than from Mitunguu (182 minutes). This demonstrates the role of road network quality in enhacing transportation of FFV products from the region. 
In view of the foregoing discussion, our empirical findings and map demonstrate that a poorly developed road network is a major obstacle facing FFV production and marketing from the Mt. Kenya region. Firstly it increases the time taken in transit from the farm to the exporting point in Nairobi, which results in product depreciation in value and or/total damage and losses. Secondly, it inhibits direct linkage between FFV farmers and respective exporters. For example one farmer stated: "The agents of the exporter do not want to go to the periphery so he goes to an agent but this agent does not want to go in the deepest periphery so he gets another agent". The dominance of middlemen results in increasingly lower earnings, since middlemen pay themselves heftily before the farmers can get their due return. In very remote regions this situation comes to a head where there is only one middleman available, which gives this middleman a monopoly. In addition, indirect contacts also lead to a cut-off of valuable information about the markets. Information flow on prices has been improved in recent years as a result of the proliferation of mobile phones in rural areas in Africa (Muto and Yamano, 2009), including Kenya (Mukhebi et al., 2007). Crucial information on the successful implementation of product and process standards demanded by EU retail chains is particularly imnportant and can usually only be given via direct support and training on the job by exporters (own interviews; see also Dannenberg, 2008).

Some limitations have to be taken into account, where further analysis could give valuable additional knowledge. As stated above, Class 4 routes could not be included in the analysis. In addition, we have not looked at the type of transportation vehicle, which also influences such transport systems (Porter, 2007). Finally, in order to give recommendations on road improvement, additional data analysis on the cost of infrastructure improvements is required.

\section{Conclusion}

The results show, that distances and time relationships to Nairobi especially in the areas away from Class 1 roads are clearly linked to poor road and respective networks. This means that road quality and connectivity influences the time and distance taken to Nairobi. Road quality and networks do not only influence the transportation of the products, but also impacts on transport cost, the quality of the products at the export market, as well as the farmers' access to the export market and business relevant information. This indicates that infrastructure projects in the Mt. Kenya region have a strong influence on the time-distances to Nairobi and can therefore contribute to the economic development of export-oriented horticultural production in the region. In this way, the improvement of transport infrastructure can lead to better integration of otherwise poorly linked farmers, enhance their earnings and contribute towards poverty alleviation efforts in the region. 


\section{Software}

The presented map was created and visualized using ESRI ArcGIS 9.3. Travel-times from Nairobi to locations in the Mount Kenya Region are shown coded in colours. All exports of Kenya's horticulture products depart from Nairobi; it is therefore the most important market place in Kenya.

\section{Acknowledgments}

We would like to thank Jürgen Schweikart (Beuth University of Applied Science), Elmar Kulke (Humboldt-University at Berlin) and Tobias Kümmerle (Potsdam Institut for Climate Impact Research) as well as our two reviewers Gina Porter, Rick Bein and the editor Mike Smith.

\section{References}

ASTER (2009) ASTER GDEM [Online]. Available from: http:/ /www.gdem.aster.ersdac.or.jp/index. jsp, [Last accessed: 12 September, 2009].

BRYCESON, D., MBARAA, T. and MAUNDER, D. (2003) Livelihoods, daily mobility and poverty in sub-Saharan Africa, Transport Reviews, 23, 177-196.

DANNENBERG, P. (2008) Challenges for African food producer in the integration in international value chains: the example of the food standard Globalgap in the horticultural production region Mt. Kenya, Zentralblatt für Geologie und Paláontologie, Teil I, 3, 337-353.

ILRI (2007) International Livestock Research Institute GIS services [Online]. Available from: http:/ / www.ilri.org/gis, [Last accessed: 12 September, 2009].

MCCULLOCH, N. and OTA, M. (2002) Export Horticulture and Poverty in Kenya, IDS Working Paper 174, Institute of Development Studies, University of Sussex, Brighton.

MITHOFER, D., NANG'OLE, E. and ASFAW, S. (2008) Smallholder access to the export market: the case of vegetables in Kenya, Outlook on Agriculture, 37, 203-211.

MUKHEBI, A., KUNDU, J., OKOLLA, A., WAMBUA, M., OCHIENG, W. and FWAMBA, G. (2007) Linking Farmers to Markets through Modern Information and Communication Technologies in Kenya, AAAE Ghana Conference 2007, 23.27.

MUTO, M. and YAMANO, T. (2009) The Impact of Mobile Phone Coverage Expansion on Market Participation: Panel Data Evidence from Uganda, World Development, 37, 1887-1896.

PORTER, G. (2007) Transport planning in sub-Saharan Africa, Progress in development studies, 7, 251257. 

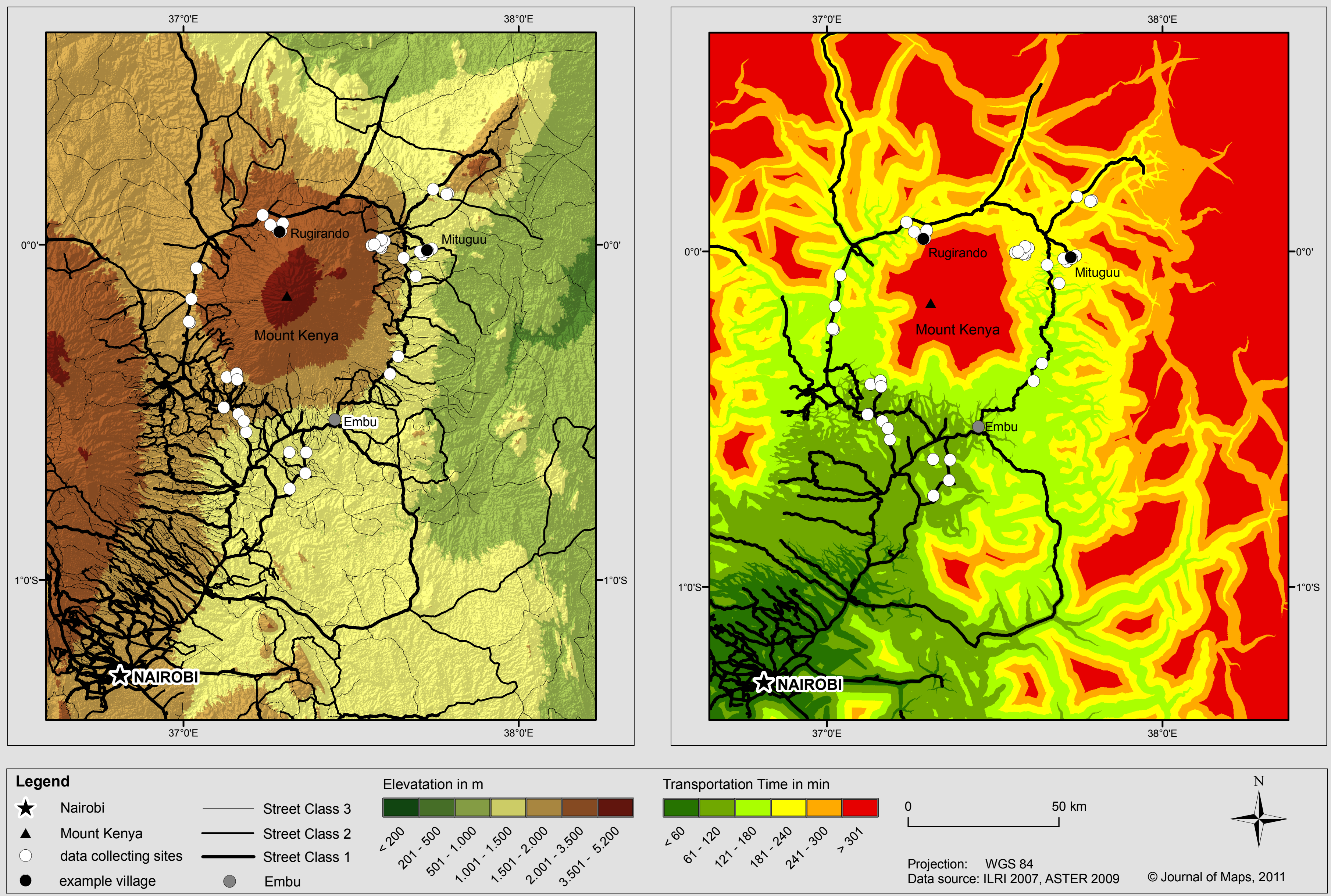

Projection: WGS 84 Data source: ILRI 2007, ASTER 2009 ○ Journal of Maps, 2011 